Saudi Journal of Medicine

Abbreviated Key Title: Saudi J Med ISSN 2518-3389 (Print) |ISSN 2518-3397 (Online) Scholars Middle East Publishers, Dubai, United Arab Emirates Journal homepage: https://saudijournals.com/sjm

Original Research Article

\title{
A Study of Hepatic Profile in Dengue in Children
}

\author{
Dr. Ananth Pai
}

Associate Professor, Department of Paediatrics, Kanachur Institute of Medical Sciences, Mangalore-Thokkottu-Konaje University Rd, Kotekar Village, Deralakatte, Karnataka 575018, India

DOI: $10.36348 /$ sjm.2020.v05i04.004 | Received: 31.03 .2020 | Accepted: 08.04.2020 | Published: 13.04 .2020

*Corresponding author: Dr. Ananth Pai

\section{Abstract}

Dengue infection of humans occurs from bites of Aedes aegypti mosquitoes. The mosquito feeds during the day and has a propensity for man-made habitats containing water. Dengue viral infection can present as three broad clinical patterns: Classic dengue, Haemorrhagic fever and Undifferentiated fever. Clinically Liver is often enlarged and tender. There are many articles which has reported the involvement of liver in this disease. The changes can be noted both clinically and also biochemically in which the enzymes are quoted elevated. These features occur in both severe and non-severe dengue cases. Therefore, monitoring for warning signs and other clinical parameters is crucial for recognising progression to critical phase. This study puts in an effort to find the hepatic profile of the patients both clinically and biochemically so as to be useful to the practising physicians.

Keywords: Clinical, Hepatic, Profile, Biochemical, Paediatric.

Copyright @ 2020: This is an open-access article distributed under the terms of the Creative Commons Attribution license which permits unrestricted use, distribution, and reproduction in any medium for non-commercial use (NonCommercial, or CC-BY-NC) provided the original author and source are credited.

\section{INTRODUCTION}

Dengue infection of humans occurs from bites of Aedes aegypti mosquitoes. The mosquito feeds during the day and has a propensity for man-made habitats containing water. Dengue viral infection can present as three broad clinical patterns: Classic dengue, Haemorrhagic fever and Undifferentiated fever. Clinically Liver is often enlarged and tender. There are many articles which has reported the involvement of liver in this disease. The changes can be noted both clinically and also biochemically in which the enzymes are quoted elevated. These features occur in both severe and non-severe dengue cases. Therefore, monitoring for warning signs and other clinical parameters is crucial for recognising progression to critical phase. This study puts in an effort to find the hepatic profile of the patients both clinically and biochemically so as to be useful to the practising physicians.

Clinically Liver is often enlarged and tender. Mildly elevated liver enzymes have been reported in dengue infection [1-3]. The enzymes can be used as a predictor for assessing the disease severity $[4$, 5]. In view of this biochemical pattern, it is possible to confuse liver involvement in dengue infection with typical acute viral hepatitis [6,7]. The presence of thrombocytopenia and persistence of fever with elevated hepatic enzymes should help [7, 8]. The changes can be noted both clinically and also biochemically in which the enzymes are quoted elevated. These features occur in both severe and nonsevere dengue cases. Therefore, monitoring for warning signs and other clinical parameters is crucial for recognising progression to critical phase. This study puts in an effort to find the hepatic profile of the patients both clinically and biochemically so as to be useful to the practising physicians.

Aims and Objectives: To study the hepatic profile in dengue.

\section{MATERIALS AND METHODS METHODOLOGY}

- The present study was conducted in the Department of General Medicine, in Kanachur Institute of Medical Sciences, Mangalore.

- 120 patients were chosen for the study who were confirmed cases of Dengue.

- The study was done from Nov 2016 to Oct 2018.

\section{Inclusion Criteria}

1. Cases confirmed with Dengue with Antigen antibody reaction test with specificity of more than 90 .

2. Cases with clinical hepatomegaly, tender hepatomegaly and elevated liver enzymes. 


\section{Exclusion Criteria}

1. Alcoholics and other known hepatocellular disease.

2. Patients on Hepatotoxic drugs, corticosteroid and other immunosuppressant therapy.
3. Previous Dengue infections who have reinfection.

All the statistical analysis is done using the ANNOVA.

\section{RESULTS}

Table-1: Age

\begin{tabular}{|l|l|l|}
\hline Total & Mean Age & SD \\
\hline 120 & 11.23 years & $3 \pm 2.17$ years \\
\hline
\end{tabular}

Table-2: Sex Distribution

\begin{tabular}{|l|l|l|}
\hline Total & Male & Female \\
\hline 120 & 64 & 56 \\
\hline
\end{tabular}

Table-3: Spectrum of Dengue related to Hepatic Disfunction

\begin{tabular}{|l|l|}
\hline Spectrum & Frequency \\
\hline Dengue without Hepatic Disfunction & 91 \\
\hline Dengue with Hepatic Disfunction & 29 \\
\hline
\end{tabular}

Table-4: Clinical Signs and symptoms related to Hepatic Disfunction

\begin{tabular}{|l|c|}
\hline Tender Hepatomegaly & 19 \\
\hline Hepatomegaly & 07 \\
\hline Frank Jaundice & 29 \\
\hline
\end{tabular}

Table-5: Enzyme

\begin{tabular}{|l|l|l|}
\hline Spectrum & SGOT (Mean) & SGPT (Mean) \\
\hline Dengue without Hepatic signs & 81.17 & 39.39 \\
\hline Dengue with Hepatic Signs & 297.83 & 101.82 \\
\hline
\end{tabular}

Table-6: Significance of rise in enzymes

\begin{tabular}{|l|l|l|l|}
\hline Value of SGOT & Significance & Value of SGPT & Significance \\
\hline 297.83 & 0.00054 & 101.82 & 0.00002 \\
\hline
\end{tabular}

\section{DISCUSSION}

Pathogenesis of Severe Dengue occurs in persons who were infected with one serotype of dengue virus previously and therefore have antibodies against that particular serotype. A second infection by a different serotype causes immunologic enhancement of antibody acquired from a previous infection. Antibodyvirus complex taken up by macrophages. Production of vascular permeability factors by macrophages. These vascular permeability factors induce plasma leakage, resulting in DHF and ultimately, DSS. Clinical features are as follows, after the incubation period of 58 days, the illness begins abruptly and is followed by the three phases-febrile, critical and recovery. Febrile Phase in patients typically develop high-grade fever suddenly that usually lasts for 2-7 days. Often accompanied by facial flushing, skin erythema, generalised body ache, myalgia, arthralgia, severe back ache ("breakbone" fever), retro-orbital pain and headache. Sore throat, injected pharynx and conjunctival injection in some patients. Anorexia, nausea and vomiting associated with High fever may cause febrile seizures in children. In some cases, temperature may decrease to nearly normal after 3-4 days and other symptoms disappear; this remission lasts for 2 days and is followed by return of fever and other symptoms. This is known as "saddleback fever" fever. Tenderness upon pressure on eyeball. A positive tourniquet test may be present. Mild haemorrhagic manifestations like petechiae and mucosal membrane bleeding may be seen. Earliest laboratory abnormality is a progressive decrease in total white cell count, which should alert the physician to a high probability of dengue. Critical Phase and the time of effervescence of fever, an increase in capillary permeability along with increasing haematocrit of critical phase. The degree of increase above the baseline haematocrit often levels may occur. This marks beginning reflects severity of plasma leakage. The period of clinically significant plasma leakage usually lasts for 24-48 hours. Progressive leukopenia followed by a rapid decrease in platelet count usually precedes plasma leakage. Patients Without an increase in capillary permeability will improve, while those with increased capillary permeability may become worse as a result of lost plasma volume. Pleural effusion and ascites may be detectable. Shock occurs when a critical volume of plasma is lost through leakage. It is often preceded by warning signs. 
During the initial stage of shock, compensatory mechanisms produce tachycardia and peripheral vasoconstriction with reduced skin perfusion, resulting in cold extremities and delayed capillary refill time. Diastolic pressure tises towards the systolic pressure and the pulse pressure narrows $(20 \mathrm{mmHg})$ as the peripheral vascular resistance increases. Patients in dengue shock often remain conscious and lucid. Later, patient decompensates and both systolic and diastolic pressures disappear abruptly. Prolonged hypotensive shock, may lead to multiorgan failure. Hypotension is usually associated with major bleeding as shock in combination with thrombocytopenia, hypoxia and acidosis which can lead to DIC. Unusual manifestations include acute liver failure, encephalopathy and cardiomyopathy. Most deaths from dengue occur in patients with profound shock, particularly if it is complicated by fluid overload.

\section{CONCLUSION}

The study has a future scope of continuation where an effort can be made to find the relation between the clinical and the biochemical enzyme levels.

\section{REFERENCES}

1. George, R., \& Lum, L. C. S. (1997). Clinical spectrum of dengue infection in Gubler DJ and Kuno G Eds Dengue and Dengue hemorrhagic fever. Washington Cab International.
2. Wiwanitkit, V. (2007). Liver dysfunction in dengue infection, an analysis of the previously published Thai cases. Journal of Ayub Medical College Abbottabad, 19(1), 10-12.

3. Itha, S., Kashyap, R., Krishnani, N., Saraswat, V. A., Choudhuri, G., \& Aggarwal, R. (2005). Profile of liver involvement in dengue virus infection. National Medical Journal of India, 18(3), 127.

4. Kumar, R., Tripathi, P., Tripathi, S., Kanodia, A., \& Venkatesh, V. (2008). Prevalence of dengue infection in north Indian children with acute hepatic failure. Annals of Hepatology, 7(1), 59-62.

5. Seneviratne, S. L., Malavige, G. N., \& De Silva, H. J. (2006). Pathogenesis of liver involvement during dengue viral infections. Transactions of the Royal society of Tropical Medicine and Hygiene, 100(7), 608-614.

6. Narayanan, M., Aravind, M. A., Ambikapathy, P., Prema, R., \& Jeyapaul, M. P. (2003). Dengue Fever-Clinical and Laboratory Parameters Associated with Complications. Dengue Bulletin, 27.

7. Jagadishkumar, K., Jain, P., Manjunath, V. G., \& Umesh, L. (2012). Hepatic involvement in dengue fever in children. Iranian journal of pediatrics, 22(2), 231-236.

8. Ashok, S. K. (2006). Dengue Illnesses. A Parthasarathy, MKC Nair, PSN Menon. IAP Textbook of Pediatrics 3rd Edition, 247-254. 